\title{
Fracture risk during extraction of well-fixed extended cementless stems : porous versus hydroxyapatite coated
}

\author{
Frederik Matthys, Jan Van Meirhaeghe, Christophe Pattyn
}

From the University Hospital of Ghent, Belgium

The concern of extensive fracturing and bone damage during implant removal has been reported for ingrowing stems, in particular in extended porous coated stems, potentially impeding successful reimplantation of a femoral revision implant and consequently debilitating patients for life.

The aim of the present study is to describe this particular complication and comparing the occurrence in porous coated and hydroxyapatite (HA) coated femoral implants.

62 consecutive revision hip replacements were performed between January 2010 and December 2016 at a single academic institution. Only revisions of a primary total hip replacement were included. All surgeries were performed by the same senior surgeon. Clinical follow-up involved examination with the Harris hip score (HHS) at 2 years post surgical intervention. Fracture occurrence and severity were compared between groups by means of the Vancouver classification for intraoperative fractures.

Overall, significant higher rates of fracturing were observed in the porous coated group $(81.8 \%, p<0.05)$ compared to the HA coated group $(43.5 \%, p<0.05)$. Of these fractures, the majority $(72,7 \%)$ were $\mathrm{B} 3$ fractures. There was a significant difference between the mean HHS in the porous-coated group versus the group with HA coating (mean Harris Hip Scores of $68,45$ vs $86,17, p=.004)$.

Surgeons have to be wary with implanting porous coated stems in primary hip arthroplasty, especially in younger patients who have a high likelihood of future revision surgery, due to the catastrophic perioperative fractures associated with the removal of these stems.

No benefits or funds were received in support of this study. None of the authors have a conflict of interest.
Keywords : Hydroxyapatite coating ; porous coated ; fracture risk ; revision surgery ; hip replacement ; Harris hip score.

\section{INTRODUCTION}

Primary hip arthroplasty is likely the most successful and cost-efficient procedure in orthopedic surgery. Patients and surgeons can expect a hip replacement to last 25 years in around $58 \%$ of patients according to National joint registries (1). With changing patient demographics, increasing life expectancy and active lifestyle at older ages, the future demand for joint replacement surgery is expected to increase by $175 \%$ by 2030 in the USA, parallel in the UK and Wales and in the Netherlands by 53 percent during the same period (2-4). A similar growth in revision surgery procedures, the outcome of which is often less favorable can therefore be expected (4-6).

\footnotetext{
Frederik Matthys, MD

Jan Van Meirhaeghe, MD

- Christophe Pattyn, MD, PHD

Department of Orthopaedic Surgery, Ghent University Hospital, Belgium

Correspondence : Frederik Matthys, Franklin Rooseveltlaan 134, 9000 Gent, Belgium. Phone : 0032496340436.

Email : frederik_matthys@hotmail.com

- 2021, Acta Orthopædica Belgica.
} 
Revision surgery is generally more expensive, provides a lesser clinical prognosis and can further decrease quality of life and activity (4). Furthermore, revision hip replacements fail much earlier than do primaries, necessitating further revisions (1). Although the outcome of primary surgery is well documented, revision surgery is far less popular in terms of survival and outcome studies (6,7-8). A particular concern that has been raised over the last two decades is the complicated removal of cementless stems, potentially impeding successful re-implantation of a femoral revision implant and consequently debilitating patients for life (9-12). Despite the massive impact on patients' quality of life and related social costs, given these complications, there is almost no literature available describing its prevalence or risk factors.

The concern of extensive fracturing and bone damage during implant removal has been reported for ingrowing stems. In particular for extended porous coated stems, where these stems seems so firmly osseointegrated that it can be a challenge extracting the implant without fracturing of the calcar and trochanters or causing severe perforation of meta- and diaphysis $(12,13)$. The aim of the present study is to describe this specific complication and to compare the occurrence in hydroxyapatite (HA) coated and porous coated femoral implants.

\section{MATERIAL AND METHODS}

62 consecutive revision hip replacements were performed between January 2010 and December 2016 at a single academic institution. Only revisions of a primary total hip replacement were included all done by the same surgeon. All revision surgery was performed through a posterolateral approach. Exclusion criteria were revisions of already revised total hip replacement, periprosthetic fractures and loosening of the femoral stem.

Permission was obtained from the university and hospital internal review boards prior to the commencement of the study. All patients gave informed consent to participate in the study.

The patient's medical record was reviewed to identify the side of the operation, the type of primary stem, the date of primary hip procedure, the type of revision performed (use of primary stem, revision stem, girdlestone or spacer). The preoperative radiographs of all hips were assessed to determine the femoral bone type with use of the isthmus ratio described by Dorr (14).

Fractures were identified by a retrospective review of the operative record and verified by examination of the postoperative radiographs by consensus of 2 clinical experts. All immediate postoperative radiographs (standard anteroposterior pelvis and anteroposterior and lateral hip x-rays) were reviewed to characterize the presence and type of intraoperative fracture. The validated Vancouver system for classifying postoperative periprosthetic fractures was adapted for use in the intraoperative period and was used to classify the intraoperative fractures. Although, in contrast to the Vancouver classification system for postoperative fractures, its reliability and validity for perioperative fractures have not been tested (15).

Despite the fact that it was invented for the description of fractures that originate in the placement of primary prostheses, the classification is valuable in describing fractures that arise during extraction of the femoral component.

According to this classification system, the femur was divided into three anatomical areas: A (the pertrochanteric region), $\mathrm{B}$ (the diaphysis), and $\mathrm{C}$ (the distal metaphyseal, or supracondylar, region). In each anatomic location, the fracture was categorized as 1 (a cortical perforation), 2 (an undisplaced linear crack), or 3 (a displaced or unstable fracture).

Clinical follow-up involved examination with Harris hip score at 2 years post surgical intervention.

\section{Statistical analysis}

Statistical analysis was conducted by using SPSS Statistics 23 software. Significance level was established at $\mathrm{P} \leq 0.05$. Fracture occurrence and severity were compared between groups by means of the Pearson Chi-square Test.

\section{RESULTS}

34 patients were included in the cohort. 11 in the non-cemented porous coated group and 23 


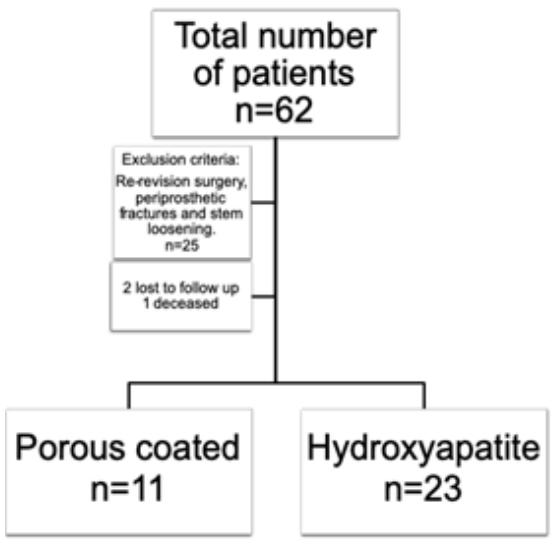

Fig. 1. - Flowchart

in the hydroxyapatite group. The porous coated group consisted of 10 females and one male. In the hydroxyapatite group we encountered 12 females and 11 males (Fig. 1.). The mean age of the cohort at the time of the procedure was 63 years. The mean age in the hydroxyapatite group was 64 years and the mean age in the porous coated group was 59 years. There was no significant difference between the mean age of the groups $(\mathrm{p}=0.331)$. (Table 1$)$

2 patients were lost to follow up because they did not want to participate in this study. 1 patient had deceased due to pulmonary complications arising after surgery.

Indications for revision surgery were aseptic loosening, metallosis, infection, wear/osteolysis, luxation and chronic pain.

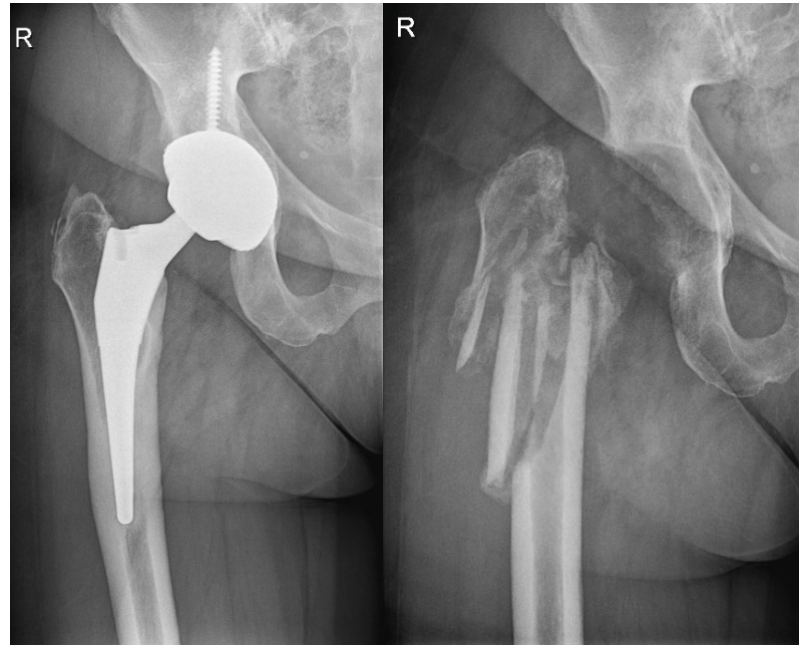

Fig. 2. - Extensive damage to the proximal femur after removal of a porous coated femoral implant.

Overall, higher rates of fracturing were observed in the porous coated group $(81.8 \%, \mathrm{p}<0.05)$ compared to the HA coated group (43.5\%). Of these fractures, the majority were B3 fractures, $72.7 \%$ of the patients in the porous coated group suffered from a B3 fracture. Only $18.2 \%$ of the patients had no fractures after removal of the femoral stem. A detailed overview of the findings is presented in table 2 .

The mean HHS at 2 years was 80.44 (34-100). The HHS in the porous coated group (68.45) was significantly lower compared to the HHS in the HA

Table 1. - Demographic Characteristics

\begin{tabular}{|l|c|c|}
\hline & Porous coated & Hydroxyapatite \\
\hline Mean age at 2 years follow up (SD) $(\mathrm{P}=0.331)$ & $59.27(13.108)$ & $64.09(13.389)$ \\
\hline Sex M/F & $1 / 10(9.1 \% / 90.9 \%)$ & $11 / 12(47.8 \% / 52.2 \%)$ \\
\hline Dorr A/B/C & $5 / 6 / 0(45.5 \% / 54.5 \% / 0 \%)$ & $11 / 12 / 0(47.8 \% / 52.2 \% / 0 \%)$ \\
\hline Mean HHS (SD) $(\mathrm{P}=0.004)$ & $68.45(14.067)$ & $86,17(15.882)$ \\
\hline
\end{tabular}

Table 2. - Fracture occurrence and severity by means of between the porous-coated and HA coated group the Vancouver classification for intraoperative fractures

\begin{tabular}{|l|c|c|c|c|c|c|}
\hline & No Fracture & Fracture & A1 & A2 & B1 & B3 \\
\hline Porous Coated (\%) & 2 & 9 & 0 & 1 & 0 & 8 \\
& $(18,2 \%)$ & $(81,8 \%)$ & $(0 \%)$ & $(9,1 \%)$ & $(0 \%)$ & $(72,7 \%)$ \\
\hline HA coated (\%) & 13 & 10 & 4 & 2 & 2 & 2 \\
$(56,5 \%)$ & $(43,5 \%)$ & $(17,4 \%)$ & $(8,7 \%)$ & $(8,7 \%)$ & $(8,7 \%)$ \\
\hline
\end{tabular}

$(\mathrm{p}<0.05)$ 
Table 3. - Hip score (HHS) at 2 years post surgical intervention between the porous-coated and HA coated group.

\begin{tabular}{|l|c|}
\hline & Mean HHS (SD) \\
\hline Porous coated & $68,45(14,067)$ \\
\hline HA coated & $86,17(15,882)$ \\
\hline Total & $80,44(17,289)$ \\
\hline
\end{tabular}

$(\mathrm{p}=0.004)$

coated group (86.17). This was a significant result $(\mathrm{p}=.004) .($ Table 3$)$

\section{DISCUSSION}

The etiology of intraoperative fractures associated with cementless fixation in primary hip arthroplasty has been well documented (16). These include several intrinsic and extrinsic factors like poor bone stock, the use of a straight stem and underreaming. These fractures are associated with increased morbidity and mortality, blood loss and a poor long term clinical function.

However, there is little literature available describing the prevalence and the risk factors of intraoperative femoral fractures in revision hip arthroplasty. This study is the first article comparing the risk of intraoperative femoral fractures in revision surgery between HA coated and porous coated femoral implants.

In the late 1980s, hydroxyapatite was applied on the implant surface in uncemented total hip arthroplasty because of its biocompatibility and osteoconductive potential (17). Some studies have shown that the use of HA coating on porouscoated stems improved clinical and radiographic outcomes compared to porous coated stems. It has been mentioned that HA coating improves the postoperative Harris Hip Score (HHS), reduce the incidence of thigh pain and reduce the incidence of femoral osteolysis (18). Other articles have demonstrated no clinical or radiographic advantages with use of HA coating (19).

We observed that the fracture risk of stem removal is highly influenced by the type of coating. Overall, the intraoperative fracture risk was double as high in porous-coated stems compared to HA coated $(81.8 \%$ vs $43.5 \%)$. Of these fractures, the majority $(72.7 \%)$ were $\mathrm{B} 3$ fractures which are unstable fractures of the pertrochanteric region extending to the diaphysis (e.g. figure 1). This type of fractures can compromise future surgical options, since they can oblige the use of long revision stems and sometimes leave no other option than a definitive girdlestone. In our study this resulted in significantly worse clinical outcomes after 2 years in the porous-coated group versus the HA coated group (mean Harris Hip Scores of 68,45 vs 86,17).

It is challenging removing osseointegrated cementless porous-coated stems due to the very irregular surface that stimulates bony ingrowth in gaps. We have the impression that it is difficult to find a proper resection plane between the implant and the femur. A thin osteotome cannot reach the osseointegrated portion distal to the metaphysis of the femur, making extraction of the stem extremely difficult. A femoral osteotomy could not overcome this problem.

In contrast, hydroxyapatite implants allow a faster closure of the gaps between stem and bone. These stems can stimulate bone ingrowth early, and after this ingrowth the coating is resorbed (20). Which results in a fixation on a relatively smoother stem surface, and subsequentially easier stem removal in case of revision surgery.

Cementless fixation in primary hip arthroplasty is associated with progressive stress shielding (21). An insufficient load transfer between bone and implant can be influenced by the difference in coating on a hip implant. There is evidence that suggest that HAcoated stems have significantly less stress shielding and superior osseous remodeling (22). We assume that this might influence the lower prevalence of perioperative fractures in the removal HA coated stems.

Limitations in our study are the small cohort and the uneven distribution of males/females in the different groups.

Further studies are needed to confirm this hypothesis. If confirmed, we should rethink the usage of these implants in primary fixation, especially in young people who may need to undergo revision surgery. 


\section{CONCLUSION}

Surgeons have to be cautious with implanting porous coated stems in primary hip arthroplasty because of the high occurrence of perioperative fractures when removing these femoral implants during revision surgery. The clinical results of these perioperative complications are devastating. Therefore, we believe that the implantation of porous coated stems in younger patients should be carefully considered.

\section{REFERENCES}

1. JT Evans, JP Evans, RW Walker, AW Blom et al. How long does a hip replacement last? A systematic review and meta-analysis of case series and national registry reports with more than 15 years of follow. The Lancet, 2019

2. Otten R, van Roermund PM, Picavet H.S.J. Trends in aantallen knie- en heupartroplastieken. Nederlands tijdschrift voor Geneeskunde 2010, 154 : A1534.

3. Kurtz S, Ong K, Lau E, Mowat F, Halpern M. Projections of primary and revision hip and knee arthroplasty in the United States from 2005 to 2030. J. Bone Joint Surg. Am. 2007 ; 89(4) : 780-5.

4. Patel A, Pavlou G, Mujica-Mota RE, Toms AD. The epidemiology of revision total knee and hip arthroplasty in England and Wales : a comparative analysis with projections for the United States. A study using the National Joint Registry dataset. Bone Joint J. 2015 ; 97-b(8) : 107681.

5. Clohisy JC, Calvert G, Tull F, McDonald D, Maloney WJ. Reasons for revision hip surgery: a retrospective review. Clin Orthop Relat Res. 2004(429) : 188-92.

6. Mardones R, Gonzalez C, Cabanela ME, Trousdale RT, Berry DJ. Extended femoral osteotomy for revision of hip arthroplasty: results and complications. J. Arthroplasty. $2005 ; 20(1): 79-83$.

7. Badarudeen S, Shu AC, Ong KL, Baykal D, Lau E, Malkani AL. Complications After Revision Total Hip Arthroplasty in the Medicare Population. J. Arthroplasty. 2017 ; 32(6) : 1954-8.

8. Postler AE, Beyer F, Wegner T, Lutzner J, Hartmann A, Ojodu I, et al. Patient-reported outcomes after revision surgery compared to primary total hip arthroplasty. Hip Int. 2017 ; 27(2) : 180-6.

9. Adelani MA, Crook K, Barrack RL, Maloney WJ, Clohisy JC. What is the prognosis of revision total hip arthroplasty in patients 55 years and younger? Clin. Orthop. Relat. Res. 2014 ; 472(5) : 1518-25.

10. Laffosse JM. Removal of well-fixed fixed femoral stems. Orthop. Traumatol. Surg. Res. 2016 ; 102(1 Suppl) : S17787.

11. Nagoya S, Sasaki M, Kaya M, Okazaki S, Tateda K, Yamashita T. Extraction of well-fixed extended porouscoated cementless stems using a femoral longitudinal split procedure. Eur. Orthop. Traumatol. 2015 ; 6(4) : 417-21.

12. Meek RM, Garbuz DS, Masri BA, Greidanus NV, Duncan CP. Intraoperative fracture of the femur in revision total hip arthroplasty with a diaphyseal fitting stem. J. Bone Joint Surg. Am. 2004 ; 86-a(3) : 480-5.

13. Adolphson PY, Salemyr MO, Skoldenberg OG, Boden HS. Large femoral bone loss after hip revision using the uncemented proximally porous-coated Bi-Metric prosthesis : 22 hips followed for a mean of 6 years. Acta Orthop. $2009 ; 80(1)$ : 14-9.

14. Dorr LD. Total hip replacement using APR system. Tech. Orthop., $1986 ; 1: 22-34$.

15. Brady OH, Garbuz DS, Masri BA, Duncan CP. The reliability and validity of the Vancouver classification of femoral fractures after hip replacement. J. Arthroplasty. $2000 ; 15: 59-62$.

16. Long-Term Outcome and Risk Factors of Proximal Femoral Fracture in Uncemented and Cemented Total Hip Arthroplasty in 2551 Hips. The Journal of Arthroplasty. 21(6 Suppl 2) : 53-9.

17. Antonio Herrera, Jesús Mateo, Jorge Gil-Albarova. Cementless Hydroxyapatite Coated Hip Prostheses. Biomed. Res. Int. $2015 ; 2015$ : 386461.

18. Yun-Lin Chen, Tiao Lin, An Liu, Ming-Min Shi, Bin Hu, Zhong-li Shi and Shi-Gui Yan. Does hydroxyapatite coating have no advantage over porous coating in primary total hip arthroplasty? A meta- analysis. J. Orthop. Surg. Res. 2015 Jan $28 ; 10: 21$.

19. Gandhi R, Davey JR, Mahomed NN. Hydroxyapatite coated femoral stems in primary total hip arthroplasty : a meta-analysis. J. Arthroplasty. 2009 Jan ; 24(1) : 38-42.

20. Alphons J. Tonino, Bart C. H. van der Wal, Ide C. Heyligers, et al. Bone Remodeling and Hydroxyapatite Resorption in Coated Primary Hip Prostheses. Clin. Orthop. Relat. Res. 2009 Feb ; 467(2) : 478-484.

21. Bobyn JD, Mortimer ES, Glassman AH, et al. Producing and avoiding stress shielding. Laboratory and clinical observations of noncemented total hip arthroplasty. Clin. Orthop. Relat. Res. 1992 Jan; (274) : 79-96.

22. Chambers B, St Clair SF, Froimson MI. Hydroxyapatitecoated tapered cementless femoral components en total hip arthroplasty. J. Arthroplasty. 2007 ; 22 : 71-74. 